\title{
Planning, design and execution of movement of naval test plant from Barrow to the north coast of Scotland
}

\author{
C. R. Ford and Captain M. D. Eldridge
}

\section{Mr Ford and Captain Eldridge}

When VSEL decided to build the PWR2 reactor in Barrow the transportation of the PWR2 unit and its secondary machinery from Barrow to Dounreay was the responsibility of Smit International, from the start of the move until the reactor unit was positioned with millimetre accuracy in the receiving building at Dounreay. The scope of the project involved transport by sea and overland and utilized five separate and quite different methods of transport: hydraulic skidding, sea towage by barge, air bag rolling, water skating and hydraulic, stabilized platform trailers. Each of these techniques on their own were well proven, but they had never before been so integrated and to such an extent as required by the sheer size of the load and the obstacles envisaged overland.

54. JMP Consultants became involved in this project as consulting engineers to Smit International as they were based in Scotland and had a reputation for road building, but this project was very different from anything the company had done before. There was nothing specifically dramatic about the construction for it is not a large complex piece of civil engineering. The challenge lay in providing satisfactory solutions in a difficult environment for what was effectively only temporary works. They had to be provided at a reasonable minimum cost to ensure that the project remained economically justifiable, and that had to be balanced against the substantial risk of possible failure that would impede the transportation process. The risk on completion was further increased by the need to carry out the work in the winter to meet a specific programme for the beaching.

Mr L. I. Wills, VSEL

What was the depth of the sand on the beach under Giant 2 when it was being levelled? Also, are there any loading characteristics for sandbags?

56. In the Paper a tolerance of $30 \mathrm{~mm}$ vertically is mentioned for the skidding track; elsewhere it was said to be $3 \mathrm{~mm}$ on the same job for skidding into the hall. In other words, VSEL set up the track in Barrow and the track in Dounreay for the skidding operation and there was never more than $3 \mathrm{~mm}$ variation in height, but the Paper implies it was $30 \mathrm{~mm}$.

\section{Mr H. J. Moorhead, Engineering Power Development Consultants}

The process which has been used here has great potential for many similar applications, particularly in the heavy construction industry. One of the main benefits this will give is that it will enable the manufacture and assembly of large and

Paper published : Proc. Instn Civ. Engrs, Part 1, 1986, 80, Aug., 885-902. 


\section{DISCUSSION}

complex items of plant and equipment, in the works including commissioning work and shipping to site complete, where there will be the minimum amount of further on-site work required.

58. How much saving was there in manufacturing at Barrow and shipping to site as in this case, compared with making it piece-small and shipping it to site for later assembly and commissioning?

\section{Mr Wills}

The terms of reference given to VSEL in the first place were that the operation should not take any longer or cost any more whether it be built at Barrow, or transported in bits and pieces and built on site. A saving had to be shown, but not loss. In the initial studies it was unsuccessful because neither the programme nor the costing could be guaranteed.

60. It was the air bag solution that turned round the whole financial situation, because before this idea thinking was in terms of multi-wheel trailers and having to build a motorway virtually to get it to site. Air bags were suddenly found to be the solution. When the idea was submitted to the Ministry of Defence a saving of $£ 1 / 2$ million was promised and six months later this was revised to a saving of $£ 1$ million. Nine months before the move it had grown to $£ 9$ million. However, that was not the whole story because changes could be incorporated in the design all the time it was at Barrow, which would not have been possible on site. So there was great flexibility with this method in that it gave the opportunity to make minor alterations in design and fitting out.

\section{Dr S. G. Tombs, Binnie \& Partners}

The writer's experience is mainly in the field of dams and barrages. Gates on such structures have to be moved either on sliding surfaces or wheels while subject to loads which might exceed $2000 \mathrm{t}$.

62. In the case of sliding bearings a common arrangement is for either PTFE or bronze pads to run on stainless steel. What materials were used to slide the PWR2 and what were the assumed and subsequently measured coefficients of sliding friction?

63. Where wheels or rollers are used to carry the load the designer is faced with choosing an allowable load between wheel or roller and the rail. There are substantial differences in allowable load when determined in accordance with standards applicable to bridge roller bearings, overhead travelling crane wheels and DIN 19704.

64. A problem with gates, particularly when renovating old works, is to match stiffness and deformations of both the gate and civil engineering supporting structure so that wheel loads may be accurately determined. Presumably a number of pads were used to support the PWR2 during the sliding operation and there might have been undulations of $2 \mathrm{~mm}$ or $3 \mathrm{~mm}$ in such a long temporary track. What measures were taken to ensure an even, or acceptable, load distribution between the pads?

65. When the barge loaded with the PWR2 required turning in the pit at the end of its journey why was this operation carried out on water skates in preference to flooding the pit and floating the barge? How was the barge transferred from the rubber air bags down on to the water skates? From what material were the water skates manufactured? They appeared to be plywood sheets fitted with rubber skirts. 
66. Binnie \& Partners have carried out a number of studies for tidal power schemes on the River Severn. There is an option between either in situ building of turbines and generators or factory assembly. The latter has a number of benefits but requires, depending on the scheme, transport of a unit load of up to $1600 \mathrm{t}$. The assembly might require loading on to a barge, off-loading at the structure in open sea conditions subject to a large tidal range and then lowering down a shaft which could be $30 \mathrm{~m}$ to $40 \mathrm{~m}$ deep. From the Authors' experience of moving the PWR2 what would be the most appropriate means of moving the turbine generator assemblies from the factory to their installed position?

\section{Sir Trevor Hughes, Welsh Office}

VSEL must have been confident of the success of the operation when they committed themselves to building at Barrow, otherwise they might have built a PWR at Barrow that could not have been sold if the promoters had not accepted it.

\section{Mr Wills}

The saving of the $£ 9$ million quoted was because in the last year much more was fitted than could ever have been done on site. However, even at the end of the project there were no two like things to compare to do a cost comparison.

69. With reference to testing, all the wiring between the control room and the control desk was completed and tested and every piece of equipment in it had had preliminary runs at Barrow before setting out. So the programme was further advanced by our being able to do all the testing beforehand.

\section{Mr Moorhead}

In the studies that the Severn Tidal Power Group did for the Severn Barrage it was considered that as well as the saving in cost in not having to transport and house expensive labour at the site, there would be a large saving in time in the case of the barrage by being able to do much of the pre-commissioning work in the factory. Much of the electrical switchgear and control equipment could also be assembled in modules, which would go in conjunction with the main heavy lift.

71. One of the problems with the Severn Barrage is that the tide range is very great, going up to $11 \mathrm{~m}$ at springs, and the question of trying to skid the heavy lift on to a fixed barrage structure and maintaining the correct elevation of the barge is a difficult one. What is the feasibility of moving large lifts from the barge to the barrage in that severe tide range?

\section{Mr P. A. Gosling, W. S. Atkins \& Partners}

In view of the potentially risky nature of the project, could the Authors outline what contingency plans they had available for various stages of the project in case their carefully laid plans did not in fact work?

\section{Mr P. W. Kelly, GEC Turbine Generators Ltd}

The water skates seem sensitive to the surface conditions on which they slide. Are they also sensitive to the slope of the sliding surface?

74. On the tow-out at Barrow, what was the cost comparison between the jacking system which was used and the use of air bags or even water skates?

\section{Captain Eldridge and Mr Ford}

With regard to $M r$ Wills' questions concerning the beach and sandbags, the depth of sand under Giant 2 was at least $2-4 \mathrm{~m}$ and certainly enough to provide a 
satisfactory cushion. Where sandbags were laid on exposed rock they were considered to have the same load characteristics as dense sand, since the material was contained - say $400-500 \mathrm{kN} / \mathrm{m}^{2}$. With regard to tolerances the skid track was set to have a $20 \mathrm{~mm}$ horizontal tolerance and a $30 \mathrm{~mm}$ vertical tolerance along its length.

76. In reply to Dr Tombs, and to start with the skidding system, the PWR unit was supported on 26 hydraulic jacks coupled in tripod series (three groups). They were nominally $100 \mathrm{t}$ jacks grouped in threes. This gave a three-legged stool effect, so that if one system failed no real bending stresses would be imparted into the unit. Those jacks were mounted on steel skidding beams welded on to the beams at the calculated positions to support the unit. In that instance nine skid beams were used (two groups of four coupled together, with a single beam under the offset section of the unit). That basically transferred the load to a length of steel beam and those beams were set into the skidding gutters, which gave them stability of direction. The friction was reduced by putting PTFE pads into the steel gutters, so that at any one time any one single beam would be supported by three or four of the PTFE pads sliding on stainless steel. Over the whole length the load was supported by 16 pads. The coefficient of friction at that stage was about $5 \%$, and a hydraulic cylinder push of about $60 \mathrm{t}$ was needed.

77. There were approximately 100 air bags underneath the barge ( 50 on each side). To transfer the barge from the air bags to the water skates it was necessary to deflate two bags at a time and replace them with one water skate, which was about $2.4 \mathrm{~m}$ by $1.5 \mathrm{~m}$ in size. The exercise was then repeated on the other side of the barge and slowly moved up its whole length deflating the air bags and lowering the barge in stages. The actual slating move was achieved by using $5 \mathrm{t}$ winches. There were six winches positioned around the pit and the barge was skated through about 70 or 80 degrees in 30 minutes and then heaved up to the retaining wall of the haul way apron. It was pulled easily, with little effort once it had started to move.

78. Water skates were chosen rather than flooding the pit and floating the barge because of the cost. The barge required a draft of $2.2 \mathrm{~m}$ before it would float, which would have meant concreting all the sides of the pit to a height of about $2.5 \mathrm{~m}$, and once the barge was in the pit the entrance would have required sealing off. So it would have been a very expensive operation.

79. During the rolling operation there was a need to adjust the pressure in the air bags to ensure smooth rolling and to prevent the barge bottoming as the profile of the ground changed. All the air bags were fitted with valves for this purpose and compressed air was supplied from a compressor carried on the barge.

80. SMIT have been involved in a project in Holland on the last estuary to be controlled by gates, which involved lifting units of $1600 \mathrm{t}$ or slightly more. That project was unique, in that some of the supports were actually built inside a dyked harbour and once 26 of these units were built the dyke was breached and flooded and each unit could float in and be lifted one at a time. If machinery is built at a factory it is then a question of getting it out on to a barge by hydraulic skidding, or whatever, and barging it out to the location and then lifting it off, which is a fairly straightforward operation.

81. In reply to $\mathrm{Mr}$ Kelly, water skates consist of a plywood sandwich surrounded by a stiff rubber skirt that presses on the ground surface. They work by the hydraulic pressure generated by the water pumped through a multitude of small holes in the lower plate which is then contained by the skirt. If the surface is 
not smooth the skirt will open up and water pressure will be lost. The fact that it was moved in that short period of time justified the time and expense spent in laying such an extremely level surface. If the surface is not smooth the operation becomes a very wet one for those involved, whereas here the floor of the pit was remarkably dry. A factory floor is normally satisfactory and skates are frequently used for moving machinery in factories. It is perfectly feasible to operate water skates on a slope and they are used for launching ships down ramps.

82. $M r$ Moorehead asked about moving large lifts where the tidal range is large. The main problem is that of the rate of rise and fall of the tide and the speed with which skidding could be achieved. Even with a sophisticated barge capable of fast ballast compensation it is unlikely to be able to cope with the rate of tidal movement in order to allow safe skidding of a heavy lift from a floating barge to a barrage structure. The 'module' barge was secured in a specially constructed cut out slipway and ballasted down such that it grounded in the cut, thus the barge could be considered a fixed structure for the purposes of the module load out. Only when the reactor module was securely in position on the barge was the ballast pumped out and the barge allowed to float.

83. To ensure feasibility of skidding from a floating barge to a fixed structure a substantial slack water window would be needed and the operator would have to be confident of completing the skidding operation within such a window. The easiest and surest way would be to position the transport barge under a floating crane and lift off the module for final positioning by the crane.

84. In reply to $\mathrm{Mr}$ Gosling's comment on the potential risk it should be emphasized that the planning of the whole operation was meticulous. Six volumes of operations manuals were produced that went into fine detail on every aspect. They also detailed a contingency plan for every operation, whether it be on the sea toe, outlining safe ports for the route, or in the event of failure of, for instance, a hydraulic hose on the skidding operation, and all these aspects were taken into account. Also, Smit gave a summary of the operations and a risk analysis before the award of contract. That risk analysis was made more detailed once the contract was signed, and VSEL themselves undertook a separate risk analysis with Lloyds and the various areas of failure were looked at and the consequences of those failures analysed. The sea tow worried many people, but Smit were not unduly concerned. They had a $2400 \mathrm{t}$ capacity ocean going barge and the load upon it was $2400 \mathrm{t}$ which in terms of their normal business was a straightforward operation.

85. With regard to the tow at Barrow it was a question of getting the unit accurately on to the barge in the cut. The centre of gravity and weight was calculated during the build period on their quality assurance and quality control procedures, but even so the weighing was done on jacks to verify those figures. These figures were passed to Smit so that they could work out exactly where the centre of gravity of the unit would be placed on the barge. The largest tidal window possible was required and it was essential that the unit was loaded accurately. Air bags do not really give the accuracy that the hydraulic skating and the gutters do. The unit itself was positioned in the receiving hall at Dounreay to within one millimetre of accuracy and the pre-commissioning which had been done meant that the unit had to match up with piping and the bits and pieces in the receiving hall which were already in place. So it was a question of accuracy, which would not be achieved with air bags or water skates. 